Tropical Journal of Pharmaceutical Research March 2016; 15 (3): 507-511

ISSN: $1596-5996$ (print); 1596-9827 (electronic)

(C) Pharmacotherapy Group, Faculty of Pharmacy, University of Benin, Benin City, 300001 Nigeria.

All rights reserved.

Available online at http://www.tjpr.org

Original Research Article

http://dx.doi.org/10.4314/tjpr.v15i3.11

\title{
Effect of Phellodendron chinense Schneid Extract on Chronic Bacterial Prostatitis Induced by Chlamydia in Rats
}

\author{
Limei Sun ${ }^{1}$, Li Zhou ${ }^{2}$, Jing Tian' and Shuyun Zheng ${ }^{1 \star}$ \\ ${ }^{1}$ Department of Dermatology, The First Affiliated Hospital of Harbin Medical University, Harbin 150001, ${ }^{2}$ Department of Urology, \\ The Second Affiliated Hospital of Harbin Medical University, Harbin 150081, Heilongjiang Province, China \\ *For correspondence: Email: zhengshuyun133494@163.com; Tel: +86 0451-85553842
}

Received: 15 May 2015

Revised accepted: 6 February 2016

\begin{abstract}
Purpose: To explore the effects of Phellodendron chinense Schneid (PCS) extract on chlamydiainduced chronic bacterial prostatitis (CBP).

Methods: Sixty 8-week-old male Sprague-Dawley rats were used in this study. Prostate index (PI) and prostate specific antigen (PSA) were determined after 4 weeks of oral administration of PCS extract (80, 160 or $320 \mathrm{mg} / \mathrm{kg}$ ) or tetracycline $(80 \mathrm{mg} / \mathrm{kg})$ and compared to PI and PSA in untreated rats with CBP and healthy control rats $(n=10)$. Chronic inflammatory cell infiltrates, acinar changes, and interstitial fibrosis were evaluated by histopathological examination. In addition, pertinent inflammatory factors,

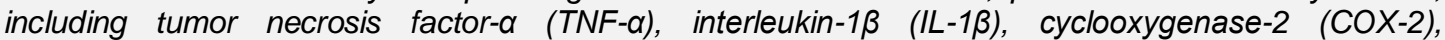
prostaglandin $E_{2}\left(P E G_{2}\right)$, transforming growth factor $\beta 1$ (TGF- $\left.\beta 1\right)$, and connective tissue growth factor (CTGF), were measured in prostate tissues using ELISA kits.

Results: High doses of PCS (160 and $320 \mathrm{mg} / \mathrm{kg}$ ) significantly decreased PI and PSA relative to model group $(p<0.01)$. PCS treatment also significantly reduced chronic inflammatory cell infiltrates and interstitial fibrosis in prostate tissue of CBP rats. In addition, TNF- $\alpha, I L-1 \beta, C O X-2, P E G_{2}, T G F-\beta 1$, and CTGF decreased in PCS-treated rats compared to untreated control $(p<0.01)$.

Conclusion: PCS extract has significant anti-inflammatory effects on chlamydia-induced CBP.
\end{abstract}

Keywords: Phellodendron chinense Schneid, Bacterial prostatitis, Inflammatory factors, Morphometric analysis, Interstitial fibrosis, Prostate specific antigen, Prostate index

Tropical Journal of Pharmaceutical Research is indexed by Science Citation Index (SciSearch), Scopus, International Pharmaceutical Abstract, Chemical Abstracts, Embase, Index Copernicus, EBSCO, African Index Medicus, JournalSeek, Journal Citation Reports/Science Edition, Directory of Open Access Journals (DOAJ), African Journal Online, Bioline International, Open-J-Gate and Pharmacy Abstracts

\section{INTRODUCTION}

Epidemiological research in the past decade has revealed that prostatitis is a major urological health problem [1,2]. There are several causes of chronic bacterial prostatitis (CBP); thus, its diagnosis and treatment have not yet been clearly defined [3].

Oral antibiotics are the typical first-line treatment for CBP. However, antibiotics do not efficiently penetrate the plasma-prostate barrier [4]. There is a need, therefore, to identify alternative treatments for CBP.

Phellodendron chinense Schneid (PCS), which is also known as huang bai and is widely cultivated in southwest China, is one of the 50 fundamental herbs of traditional Chinese medicine. PCS has immune-modulation [5], anti-tumor [6], and antibacterial $[7,8]$ properties.

The aim of the present study was to evaluate the therapeutic effects and mechanisms of action of PCS extract on chlamydia-induced CBP. 


\section{EXPERIMENTAL}

\section{Materials}

Herbal samples of Phellodendron chinense Schneid were collected from Bozhou City, Anhui Province in China in May 2014. Taxonomic identification of the plant was performed by Professor Wuke Wang of Harbin Medical University in China. A herbarium specimen (no. PCS 201307015) was deposited in the College of Pharmacy, Harbin Medical University, China for future reference.

The same batch of PCS was dried, first in an oven, and then by freeze drying. One gram of powder was equivalent to approximately $1.5 \mathrm{~g}$ of crude sample. The yield was $66.67 \%$. The aqueous extract of PCS was obtained by steeping this dried PCS in water for $1 \mathrm{~h}$ at $60{ }^{\circ} \mathrm{C}$ for three times.

\section{Animals}

Eight week old male Sprague-Dawley rats (250$300 \mathrm{~g}$ ) were provided by the Experimental Animal Center of Harbin Province (certificate no. SYXK2005-0004). The animals had free access to food and water and were allowed to acclimate to the laboratory environment for at least 1 week prior to the experiments. This study was approved by the Animal Care and Use Committee of Harbin Medical University (approval ref no. 20120805) and was carried out in compliance with Directive 2010/63/EU on the Handling of Animals Used for Scientific Purposes [9].

The rats were randomly divided into 6 groups of 10 rats each: healthy group(not have chlamydiainduced CBP), model group, positive treatment group (80 mg/kg tetracycline), and three PCStreated groups (80, 160, and $320 \mathrm{mg} / \mathrm{kg}$ doses). Tetracycline and PCS extract were both dissolved in water. Treatments were administered orally once per day for 4 weeks.

\section{Chronic bacterial prostatitis model (CBP)}

CBP was induced using previously described procedures [10]. Briefly, a strain of Chlamydia (Z17, O2:K1:H-) was grown overnight at $37^{\circ} \mathrm{C}$ in a tryptic soy broth (TSB) in a shaker. Cells were spun, washed three times, and re-suspended in TSB to obtain 108 cells $/ \mathrm{mL}$.

Rats were anaesthetized with ether, and the genital area was cleaned with $70 \%$ alcohol and subsequently catheterized with a lubricated sterile polyethylene tube $(0.9-\mathrm{mm}$ outer diameter, 2.5-cm length). An insulin syringe was attached to the needle, and $0.2 \mathrm{~mL}$ of the bacterial suspension containing $1 \times 10^{8}$ colony-forming units per $\mathrm{mL}$ of chlamydia was injected into the prostatic urethra. Anesthesia was maintained for $1 \mathrm{~h}$ to prevent urinary leakage due to movement of the rat and to allow a sufficient time for bacteria to invade the prostate.

\section{Measurement of prostate index (PI) and prostate specific antigen (PSA)}

The prostatic index (PI) of all rats was computed as prostate weight $(\mathrm{mg}) /$ body weight $(\mathrm{g})$. Blood was collected by removing the eyeball. The blood sample was allowed to clot, and the serum was separated at $3500 \mathrm{r} / \mathrm{min}$ for $15 \mathrm{~min}$. ELISA kits (provided by Shenzhen Xin-Bo-Sheng Biological Technology Co Ltd, Shenzhen, China) then were used to determine the level of prostate specific antigen (PSA).

\section{Measurement of tumor necrosis factor- $\alpha$ (TNF- $\alpha$ ) and interleukin-1 $\beta$ (IL-1 $\beta$ )}

Pro-inflammatory cytokines tumor necrosis factor- $\alpha$ (TNF- $\alpha)$ and interleukin-1 $\beta$ (IL-1 $\beta$ ) were measured in prostate tissue from CBP group and PCS-treated groups using commercial ELISA assay kits (Shenzhen Xin-Bo-Sheng Biological Technology Co Ltd) according to the manufacturer's instructions. Samples and standards were run in duplicate and resulting data were averaged. Results are expressed in $\mathrm{pg} / \mathrm{mL}$.

Measurement of $\mathrm{PGE}_{2}, \mathrm{COX}-2, \mathrm{TGF}-\beta 1$, and CTGF

The effects of CBP on prostaglandin $E_{2}\left(P_{G} E_{2}\right)$, cyclooxygenase-2 (COX-2), transforming growth factor $\beta 1$ (TGF- $\beta 1$ ), and connective tissue growth factor (CTGF) levels were measured in prostate tissues using commercial ELISA kits (Shenzhen Xin-Bo-Sheng Biological Technology Co Ltd). All assays were performed in $10 \%$ prostate supernatant in accordance with the manufacturer's instructions. Results are expressed in $\mathrm{pg} / \mathrm{mL}$.

\section{Histopathological examination}

Prostates were excised and fixed in $4 \%$ paraformaldehyde for histopathological studies. Sections of prostates were dehydrated by ethanol, and 4 - $5 \mathrm{~mm}$ sections were cut, stained with hematoxylin and eosin, and examined under a light microscope (Beijing Olympus Co. Ltd., Beijing China). 


\section{Statistical analysis}

Data are presented as mean \pm standard deviation (SD), and analyzed by one-way analysis of variance (ANOVA) followed by Tukey's multiple comparison test in Statistical Package for the Social Sciences software (SPSS for Windows, version 16.0, SPSS, Inc., Chicago, IL, USA). Differences were considered statistically significant at $p<0.05$.

\section{RESULTS}

\section{Effect of PCS extract on PI and PSA}

The effects of 4 weeks of oral administration of PCS extract on PI and PSA levels are summarized in Table 1. Compared with healthy controls, PI and PSA increased to $2.4 \mathrm{mg} / \mathrm{g}$ and $327.8 \mathrm{pg} / \mathrm{mL}$, respectively $(p<0.01)$, in the Chlamydia-induced CBP group. After treatment with PCS extract, PI and PSA significantly decreased $(p<0.01)$. The largest decrease was observed in response to the highest dose of PCS extract. PI and PSA levels also decreased after 4 weeks of tetracycline administration $(p<0.01)$.

\section{Effect of PCS extract on TNF- $\alpha$ and IL-1 $\beta$}

The effects of 4 weeks of oral administration of PCS extract on TNF- $\alpha$ and IL-1 $1 \beta$ levels are summarized in Table 2. Compared with healthy controls, TNF- $\alpha$ significantly increased in Chlamydia-induced CBP rats $(p<0.01)$. TNF- $\alpha$ was significantly decreased by 160 and 320 $\mathrm{mg} / \mathrm{kg}$ doses of PCS extract compared with the model group $(p<0.05$ and $p<0.01$, respectively). Similarly, IL-1 $\beta$ was significantly increased in chlamydia-induced CBP rats compared with healthy controls $(p<0.01)$, and significantly decreased by 160 and $320 \mathrm{mg} / \mathrm{kg}$ doses of PCS extract $(p<0.01)$. Tetracycline also significantly decreased TNF- $\alpha$ and IL-1 $\beta$ levels $(p<0.01)$.

\section{Effect of PCS extract on $\mathrm{PGE}_{2}$, COX-2, TGF- $\beta 1$, and CTGF}

The effects of 4 weeks of oral administration of PCS extract on $\mathrm{PGE}_{2}$, COX-2, TGF- $\beta 1$, and CTGF levels are summarized in Table 3. $\mathrm{PGE}_{2}$, COX-2, TGF- $\beta 1$, and CTGF were all significantly increased in chlamydia-induced CBP rats $(p<$ 0.01 ). After treatment with $P C S$, both $P E_{2}$ and TGF- $\beta 1$ significantly decreased in a dosedependent manner $(p<0.05)$. Similarly, CTGF and COX-2 were both significantly decreased by 160 and $320 \mathrm{mg} / \mathrm{kg}$ doses of PCS extract $(p<$ 0.01 ). Tetracycline also significantly decreased $\mathrm{PGE}_{2}(p<0.01)$, COX-2 $(p<0.05)$, TGF- $\beta 1$ ( $p<$ $0.05)$, and CTGF $(p<0.01)$ levels.

Table 1: Effect of PCS extract on PI and PSA levels

\begin{tabular}{lccc}
\hline Group & Dose $\mathbf{( m g / k g})$ & PI $(\mathbf{m g} / \mathbf{g})$ & PSA $(\mathbf{p g} / \mathbf{m L})$ \\
\hline Healthy & - & $0.8 \pm 0.2$ & $119.3 \pm 10.8$ \\
Model & - & $2.4 \pm 0.2$ & $327.8 \pm 20.5$ \\
Tetracycline & 80 & $1.5 \pm 0.4$ & $179.4 \pm 15.6^{\pi \pi}$ \\
PCS-L & 80 & $1.6 \pm 0.3$ & $271.6 \pm 30.4$ \\
PCS-M & 160 & $1.3 \pm 0.2$ & $178.7 \pm 20.8^{\prime}$ \\
PCS-H & 320 & $1.0 \pm 0.1^{\cdots}$ & $149.2 \pm 13.5^{\prime \prime}$ \\
\hline
\end{tabular}

Data are expressed as the mean \pm SD; $n=10$ in each group; PCS-L = low dose of PCS extract; PCS-M = moderate dose of PCS extract; PCS-H = high dose of PCS extract; ${ }^{*} p<0.05,{ }^{* *} p<0.01$ vs. model group

Table 2: Effect of PCS extract on TNF- $\alpha$ and IL-1 $\beta$ levels

\begin{tabular}{lccc}
\hline Group & Dose $(\mathbf{m g} / \mathbf{k g})$ & TNF- $\alpha(\mathrm{pg} / \mathrm{mL})$ & IL-1 $\beta(\mathrm{pg} / \mathbf{m L})$ \\
\hline Healthy & - & $99.6 \pm 8.5^{\star *}$ & $73.6 \pm 6.4^{* *}$ \\
Model & - & $158.4 \pm 13.2$ & $174.1 \pm 12.1$ \\
Tetracycline & 80 & $119.5 \pm 7.4^{* *}$ & $120.4 \pm 11.7^{* *}$ \\
PCS-L & 80 & $146.3 \pm 15.8$ & $149.7 \pm 14.8$ \\
PCS-M & 160 & $131.7 \pm 8.2^{*}$ & $122.5 \pm 8.7^{* *}$ \\
PCS-H & 320 & $122.5 \pm 9.3^{* *}$ & $98.6 \pm 10.3^{* *}$
\end{tabular}

Data are expressed as the mean \pm SD $(n=10)$; PCS-L = low dose of PCS extract; PCS-M = moderate dose of PCS extract; PCS-H = high dose of PCS extract; ${ }^{*} p<0.05, \quad{ }^{* *} p<0.01$ vs. model group 
Table 3: Effect of PCS extract on $\mathrm{PGE}_{2}$, COX-2, TGF- $\beta 1$, and CTGF levels

\begin{tabular}{|c|c|c|c|c|c|}
\hline Group & $\begin{array}{c}\text { Dose } \\
(\mathrm{mg} / \mathrm{kg})\end{array}$ & $\begin{array}{c}\text { PGE }_{2} \\
\text { (pg/mL) }\end{array}$ & $\begin{array}{c}\text { COX-2 } \\
\text { (pg/mL) }\end{array}$ & $\begin{array}{l}\text { TGF- } \beta 1 \\
\text { (pg/mL) }\end{array}$ & $\begin{array}{c}\text { CTGF } \\
\text { (pg/mL) }\end{array}$ \\
\hline Healthy & & $66.5 \pm 3.6$ & $11.5 \pm 1.3$ & $70.7 \pm 4.1^{1}$ & $57.2 \pm 3.4$ \\
\hline Model & & $126.6 \pm 6.7$ & $33.5 \pm 3.4$ & $146.2 \pm 12.7$ & $117.4 \pm 5.8$ \\
\hline Tetracycline & 80 & $85.4 \pm 5.9$ & $15.2 \pm 2.8$ & $110.4 \pm 8.6$ & $89.4 \pm 6.1^{n}$ \\
\hline PCS-L & 80 & $102.6 \pm 4.8$ & $26.1 \pm 4.3$ & $126.4 \pm 9.6$ & $115.6 \pm 7.1$ \\
\hline PCS-M & 160 & $93.4 \pm 6.4$ & $17.1 \pm 3.2^{\prime \prime}$ & $111.6 \pm 7.6$ & $93.3 \pm 8.4$ \\
\hline PCS-H & 320 & $81.4 \pm 4.5^{\pi \pi}$ & $14.5 \pm 2.5^{\pi \times}$ & $87.5 \pm 8.1^{\pi \pi}$ & $72.4 \pm 6.3^{\pi \pi}$ \\
\hline
\end{tabular}

Data are expressed as the mean \pm SD $(n=10)$; PCS-L = low dose of PCS extract; PCS-M = moderate dose of PCS extract; PCS-H = high dose of PCS extract; ${ }^{*} p<0.05, \quad p<0.01$ vs. model group

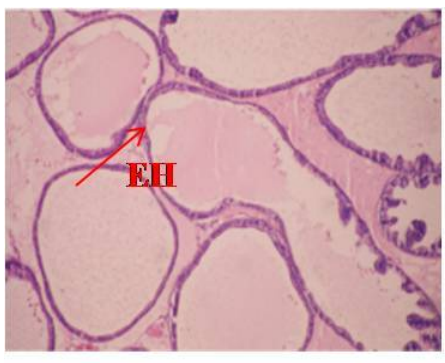

$\mathbf{A}$

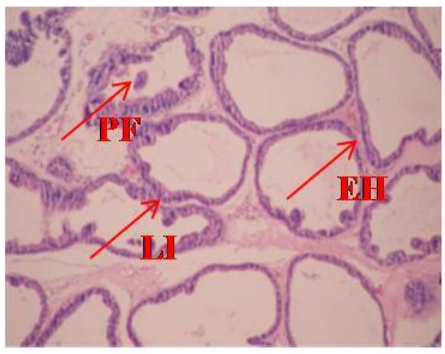

D

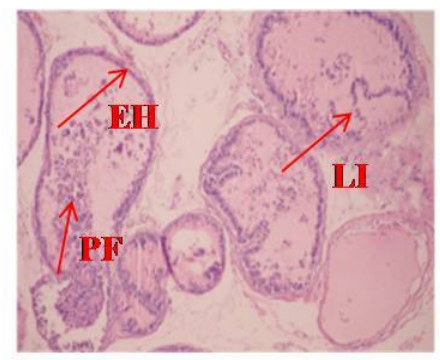

B

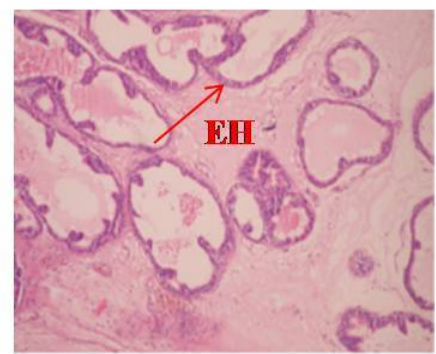

$\mathbf{E}$

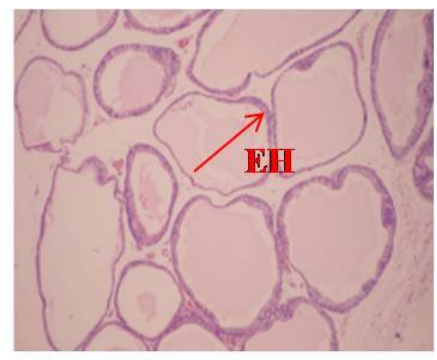

C

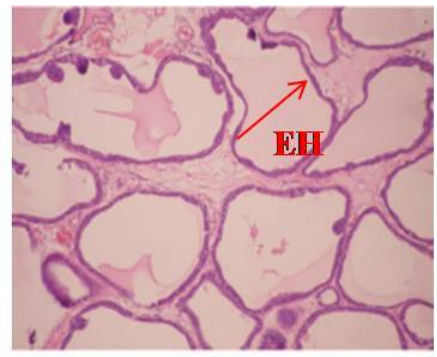

F

Figure 1: Effect of PCS extract on the histomorphology of prostate tissues in rats. Hematoxylin and eosin stained (x 200) prostate cells in the A: healthy group; B: model group; C: positive group (80 mg/kg tetracycline); D: 80 $\mathrm{mg} / \mathrm{kg}$ PCS extract group; E: $160 \mathrm{mg} / \mathrm{kg}$ PCS extract group; F: $320 \mathrm{mg} / \mathrm{kg}$ PCS extract group; EH = epithelial height; $P F=$ papillary fronds; $\mathrm{LI}=$ leukocyte infiltration

\section{Histopathological characteristics}

No change in the morphological structure of the prostate gland was found in healthy controls (Figure 1A). In contrast, severe diffuse chronic inflammation characterized by leukocyte infiltration and papillary frond protrusion into the gland cavities, as well as an increase in prostatic epithelial height, were observed in the lateral lobe of the prostate in chlamydia-induced CBP rats (Figure 1B). However, these changes were significantly suppressed in rats administered tetracycline or PCS extract, especially at doses of 160 and $320 \mathrm{mg} / \mathrm{kg}$ of PCS extract per day (Figure 1E-F).

\section{DISCUSSION}

PCS is a traditional Chinese medicine used for the treatment of prostatitis in China. In our study, experimental CBP was induced by Chlamydia, which was confirmed by increased levels of PI and PSA. Four weeks of oral administration of PCS extract significantly decreased PI and PSA, as well as several inflammatory markers, including COX-2, $\mathrm{PGE}_{2}, \mathrm{TGF}-\beta 1$, and CTGF. Thus, the administration of PCS extract for 4 weeks significantly inhibited the development of chronic inflammation and fibrosis in prostatic tissue $[11,12]$.

IL-1 $\beta$ is a pro-inflammatory cytokine [13], and TNF- $\alpha$ is rapidly produced by macrophages in response to tissue damage [14]. Studies have shown that the activation of transcription factor NF-KB by TNF- $\alpha$ is one of several actions of TNF- $\alpha$ [15]. Cytokine-based therapies have been found to be useful in preventing the progression of chronic prostatitis [16]. In the present study, increased levels of TNF- $\alpha$ and IL-1 $\beta$ in chlamydia-induced CBP rats were suppressed by 
160 and $320 \mathrm{mg} / \mathrm{kg}$ of PCS extract. Similarly, increased levels of COX-2 and $\mathrm{PGE}_{2}$ in chlamydia-induced $\mathrm{CBP}$ rats were reversed by PCS treatment. Therefore, the anti-CBP effect of PCS extract may be related to its antiinflammatory properties.

TGF- $\beta$, which is the most extensively studied molecule in fibrosis, stimulates the production of reactive oxygen species in various types of cells [17-19]. In addition, CTGF has been implicated in fibroblast proliferation, cellular adhesion, angiogenesis, and extracellular matrix synthesis [20-22]. Our results indicate that PCS extract suppresses CBP-enhanced TGF- $\beta 1$ expression. Our results also suggest that PCS extract regulates the CTGF signaling pathway following TGF- $\beta 1$ stimulation.

\section{CONCLUSION}

The results of this study demonstrate that PCS has a significant anti-inflammatory effect on chronic bacterial prostatitis in rats. Further development in vivo studies are required to its therapeutic potentials.

\section{REFERENCES}

1. Motrich RD, Maccioni M, Molina R, Tissera A, Olmedo J, Riera CM, Rivero VE. Presence of INF gammasecreting lymphocytes specific to prostate antigensin a group of chronic prostatitis patients. Clin. Immunol 2005; 116: 149-157.

2. Werner WH. Anti-inflammatory therapies for chronic prostatitis. Eur. Urol. Suppl 2003; 2: 30-33.

3. Nickel JC, Olson ME, Costerton JW. Rat model of experimental bacterial prostatitis. Infection. 1991; 19: 126-130.

4. Nickel JC. Prostatitis and related conditions. In: Walsh $P C$, Reik $A B$, Vaughan $E D \mathrm{Jr}$, Wein $A J$, editors. Campbell's urology. 8thed. Philadelphia: Saunders; 2002. p. 604-630.

5. Park SD, Lai YSH, Kim CHH. Immunopontentiating and antitumor activities of the purified polysaccharides from Phellodendron chinese Schneid. Life Sci 2004; 75 : 2621-2632.

6. Jung HW, Jin GZ, Kim SY. Neuroprotective effect of methanol extract of Phellodendri Cortex against 1methyl-4-phenylpyridinium (MPP ${ }^{+}$-induced apoptosis in PC-12 cells. Cell Biology International. 2009; 33: 957963.

7. Chen L, Di DL. Study on Antibacterial Effect in vitro of Phellodendron amurense Rupr (PAR). Lishizhen Med. and Mate Medical Res. 2006; 17: 759-760.

8. Xian YF, Mao QQ. Comparison on the anti-inflammatory effect of Cortex Phellodendri Chinensis and Cortex
Phellodendri Amurensisin 12-O-tetradecanoyl-phorbol13-acetate-induced ear edema in mice. $J$ Ethnopharmacol 2011; 137: 1425-1430.

9. European Commission. Directive 2010/63/EU on the protection of animals used for scientific purposes [cited 2013 Jan 16]. Available from:http://ec.europa.eu/environ ment/chemicals/lab_animals/legislation_en.htm.

10. Dong WS, Chang HH, Yun SJ. Anti-inflammatory and antimicrobial effects of garlic and synergistic effect between garlic and ciprofloxacin in a chronic bacterial prostatitis rat model. Int J Antimicrob Agent 2009; 34: 215-219.

11. Nadler RB, Koch AE, Calhoun EA, Campbell PL, Pruden $D L$, Bennett CL, Yarnold PR, Schaeffer AJ. IL-1beta and TNF-alpha in prostatic secretions are indicators in the evaluation of men with chronic prostatitis. J. Urol. 2000; 164: 214-218.

12. Tsunemori $H$, Sugimoto $M$, Xia Z, Taoka R, Oka $M$, Kakehi $Y$. Effect of the phytotherapeutic agent Eviprostat on inflammatory changes and cytokine production in a rat model of nonbacterial prostatitis. Urology 2011; 77: e1515.

13. Dinarello CA. Interleukin-1, interleukin-1 receptors and interleukin-1receptor antagonist. Int. Rev. Immunol. 1998; 16: 457-499.

14. Beutler B, Cerami A. The biology of cachectin/TNF-a primary mediator of the host response. Annu. Rev. Immunol. 1989; 7: 625-655.

15. Tahir M, Rehman $M U$, Lateef $A$, Khan R, Khan $A Q$, Qamar W, Ali F, O'Hamiza O, Sultana S. Diosmin protects against ethanol-induced hepatic injury via alleviation of inflammation and regulation of TNF-alpha and NF-kappa B activation. Alcohol. 2013; 47: 131-139.

16. Lu BY, Cai HF, Huang, WS, Wu XQ, Luo YX, Liu L, Zhang, $Y$. Protective effect of bamboo shoot oil on experimental nonbacterial prostatitis in rats. Food. Chem. 2011; 124: 1017-1023.

17. Liu RM, Gaston KA. Oxidative stress and glutathione in TGF-beta-mediated fibrogenesis. Free. Radic. Biol. Med. 2010; 48: 1-15.

18. Untergasser G, Gander R, Lilg C, Lepperdinger G, Plas $E$, Berger $P$. Profiling molecular targets of TGF-beta1 in prostate fibroblast-to-myofibroblast trans differentiation. Mech. Ageing. Dev. 2005; 126: 59-69.

19. Leask A, Abraham DJ. TGF-beta signaling and the fibrotic response. FASEB J. 2004; 18: 816-827.

20. Lau LF, Lam SC. The CCN family of angiogenic regulators: the integrin connection. Exp. Cell. Res. 1999; 248: 44-57.

21. Kular L, Pakradouni J, Kitabgi P, Laurent M, Martinerie C. The CCN family: a new class of inflammation modulators? Biochimie. 2011; 93: 377-388.

22. Borthwick LA, Wynn TA, Fisher AJ. Cytokine mediated tissue fibrosis. Biochim. Biophys. Acta. 2013; 1832: 1049-1060. 